\title{
A Retrospective Descriptive Analysis of Non- physician-performed Prehospital Endotracheal Intubation Practices and Performance in South Africa
}

Craig Alexander Wylie ( $\nabla$ craig.wylie@uct.ac.za )

University of Cape Town Faculty of Health Sciences https://orcid.org/0000-0003-2168-4838

Farzana Araie

University of Cape Town Faculty of Health Sciences

Clint Hendrikse

University of Cape Town Faculty of Health Sciences

Jan Burke

University of Cape Town Faculty of Health Sciences

Ivan Joubert

University of Cape Town Faculty of Health Sciences

Anneli Hardy

University of Cape Town Faculty of Health Sciences

Willem Stassen

University of Cape Town Faculty of Health Sciences https://orcid.org/0000-0002-1486-4446

\section{Research Article}

Keywords: Prehospital emergency care, airway management, endotracheal intubation, South Africa

Posted Date: February 23rd, 2022

DOI: https://doi.org/10.21203/rs.3.rs-1216356/v1

License: (c) (1) This work is licensed under a Creative Commons Attribution 4.0 International License.

Read Full License 


\section{Abstract}

Introduction: Prehospital advanced airway management (PHAAM), including endotracheal intubation (ETI), is one of the most commonly performed advanced life support skills. In South Africa, prehospital ETI is performed by non-physician prehospital providers. This practice has recently come under immense international scrutiny due to lower first pass (FPS) and overall success rates, a high incidence of adverse events (AEs), and limited data regarding the impact of ETI on mortality. The aim of this study was to describe non-physician ETI in a South African national sample in terms of patient demographics, indications for intubation, means of intubation and success rates. A secondary aim was to determine what factors were predictive of first pass success.

Methods: This study was a retrospective chart review of prehospital ETIs performed by non-physician prehospital providers, between the periods of 01 January 2017 to 31 December 2017. Two national private Emergency Medical Services (EMS) and one provincial public EMS were sampled. Data was analysed descriptively and summarised. Logistic regression was performed to evaluate the effect of demographics, clinical factors, and risk and aggravating factors for difficult intubation on the likelihood of FPS.

Results: A total of 926 cases were included. The majority of cases were adults ( $n=781,84.3 \%)$ and male $(n=553,57.6 \%)$. The most common pathologies requiring emergency treatment were head injury, including traumatic brain injury $(T B I, n=328,35.4 \%)$, followed by cardiac arrest $(n=204,22.0 \%)$. The mean time on scene was 46 minutes $(S D=28.3)$. The most cited indication for intubation was decreased level of consciousness ( $n=515,55.6 \%)$, followed by cardiac arrest $(n=242,26.9 \%)$ and ineffective ventilation $(n=96,10.4 \%)$. RSI ( $n=344,37.2 \%)$ was the most common approach. The FPS rate was $75.3 \%$, with an overall success rate of $95.7 \%$. Intubation failed in $33(3.6 \%)$ patients. The need for ventilation was inversely associated with FPS ( $O R=0.42,95 \% \mathrm{Cl}: 0.20-0.88, \mathrm{p}=0.02)$; while deep sedation $(\mathrm{OR}=0.56$, $95 \% \mathrm{Cl}: 0.36-0.88, \mathrm{p}=0.13)$ and no drugs $(\mathrm{OR}=0.47,95 \% \mathrm{Cl}: 0.25-0.90, \mathrm{p}=0.02)$ compared to RSI was less likely to result in FPS. Increased scene time (OR $=0.99,95 \% \mathrm{Cl}: 0.985-0.997, p<0.01)$ was inversely associated FPS.

Conclusion: In this sample of ground-based EMS non-physician ETI, we found success rates similar to those reported in the literature. More research is needed to determine AE rates and the impact of ETI on patient outcome. There is an urgent need to standardise PHAAM reporting in South Africa.

\section{Introduction}

Prehospital advanced airway management (PHAAM) is one of the most commonly performed invasive interventions in the out-of-hospital setting. ${ }^{1-3}$ Protecting the airway of a critically ill or injured patient and facilitating adequate ventilation and oxygenation is an essential part of prehospital emergency care. ${ }^{2}$ The skill of endotracheal intubation (ETI) is normally reserved for only the highest qualified prehospital providers and, depending on the prehospital system and available resources, often only to anaesthetists 
or emergency physicians who practice in the prehospital phases of care. ${ }^{2}$ Owing to conflicting results on the safety and impact on mortality of prehospital ETI performed by non-physicians, this practice has come under immense scrutiny in recent times. ${ }^{2}$

Controversies surrounding non-physician performed ETI relate mostly to lower first pass and overall success rates, ${ }^{4}$ or poorer outcome associated with prehospital ETI, especially in traumatic brain injury. 5,6 A more recent systematic review and meta-analysis found that a marginal difference in the overall ETI rates between physicians (99\%) and non-physicians (97\%) and a 10\% difference in first pass intubation success when comparing physicians (88\%) versus non-physicians (78\%). Fouche et. al. also reported a higher rate of adverse events (AEs) among non-physicians, which may be explained by a lower FPS rate in this cohort. ${ }^{2}$ Almost all cited studies originate from a higher income country (HIC) setting.

There are important differences in prehospital and emergency care systems in low-to middle-income countries (LMICs) that data originating from HICs do not take into consideration. Firstly, prehospital services in LMICs are predominantly non-physician based ${ }^{7}$ and are likely to stay that way for the foreseeable future because of a critical shortage of physicians in these settings. ${ }^{8}$ Secondly, LMICs are often characterised by long distances to healthcare facilities, ${ }^{9}$ which my significantly prolong prehospital times. Thirdly, patients also experience many barriers to accessing emergency care ${ }^{10}$ and thus might take longer to present or with well-progressed critical disease. Lastly, LMICs suffer from a unique burdens of disease including injury, infectious disease (including HIV and TB) and chronic non-communicable diseases. ${ }^{9}$ All these factors may make the need for earlier critical interventions in the prehospital setting, including PHAAM and prehospital ETI. ${ }^{11}$

South Africa has one of the most developed EMS systems on the African continent. ${ }^{7}$ Here, prehospital advanced life support non-physicians have been performing prehospital ETI for well over a decade. ${ }^{11,12}$ Yet, there is still a paucity of literature to assess the safety and impact of non-physician performed ETI originating from LMICs, including South Africa. Where literature exists, it frequently originates from a single centre, ${ }^{6,11}$ student paramedics ${ }^{13}$ or from the aeromedical environment. ${ }^{14}$ The aim of this study was to describe non-physician ETI in a South African national sample in terms of patient demographics, indications for intubation, means of intubation and success rates. A secondary aim was to determine what factors are predictive of first pass success.

\section{Methods}

We performed a retrospective chart review of pre-hospital ETIs performed by non-physician prehospital providers, between the periods of 01 January 2017 to 31 December 2017. Two national private EMS and one provincial public EMS were sampled. This manuscript has been prepared in accordance with the The REporting of studies Conducted using Observational Routinely-collected health Data (RECORD) extension of the Strengthening the Reporting of Observational Studies in Epidemiology (STROBE) checklist. ${ }^{15}$ 


\section{Setting}

South Africa is an upper-middle income country with an estimated population of approximately 58 million people. There are two distinct healthcare systems, private healthcare and state healthcare. State healthcare is that provided by the South African government to citizens while private healthcare is only accessible to patients through funds to pay for the services, or those with healthcare insurance aid. Only $17 \%$ of South Africans currently belong to a healthcare insurance scheme. ${ }^{16}$ In the context of EMS though, private EMS are mandated by the constitution to provide emergency care to all patients regardless of their ability to pay or insurance status.

In South Africa prehospital emergency care is provided by non-physician prehospital care providers. Although many cadres of prehospital providers exist, only advanced life support providers may perform endotracheal intubation. These providers may either be qualified through a vocational training (one year certificate course) or higher education training (three-year university diploma or four-year university honours degree). While this changed in 2020, during the study period, certificate and diplomat prehospital providers were able to intubate only via deep sedation (or no sedation) while degree holders were licensed to perform rapid sequence intubation (RSI). After 2020, endotracheal intubation of any form is reserved for degree paramedics only. 17,18

\section{Sample and sampling}

Instances of ETI were identified in a variety of ways, depending on the type of the patient report form or archiving systems of each EMS. For the first national private EMS, hand-written, scanned patient report forms (PRFs) of all patients who were intubated by non-physician prehospital providers, between the periods of 01 January 2017 to 31 December 2017 were eligible for analysis. A standard checkbox on the patient report form indicates that intubation was performed, as well as the number of intubation attempts. Both of these are captured onto a central billing system before the form is scanned for archiving. This allowed for the easy identification of intubated patients.

Both the second national private and provincial public EMS utilise electronic patient report forms (ePRFs). For this reason, an extract of cases that fit our inclusion criteria were extracted. In these cases, the number of intubation attempts is not a field in the ePRF and thus has to be extracted from the narrative, typed clinical notes of the prehospital care provider.

Any patients who were intubated by a physician, those who underwent intubation for interfacility transfer, and those intubated on the aeromedical platforms were excluded from analysis. Patients who were intubated by crew members from another service who were attending to the same scene were also excluded.

\section{Data extraction and definitions}

After specific training in the research aims, objectives, data variables, and the contents of the PRFs, data were extracted according to a dedicated, standard data abstraction form by a data capturer with 
experience in clinical administration and the authors (FA, JB). Regular meetings between the data capturers and authors were held to ensure credibility of the extraction process. The data extraction form was based on the Utstein reporting guidelines for prehospital advanced airway management. ${ }^{19}$

An intubation attempt was defined as the placement of a laryngoscope blade into the pharynx with the aim of exposing the glottis. An intubation success was defined as placement of the distal end of the endotracheal tube and cuff into the patient's trachea as confirmed by waveform capnography and/or chest auscultation. First Pass Success (FPS) refers to the situation where intubation was successful after a single attempt. If intubation was successful after more than one attempt, this was referred to as Overall Success. A failed intubation was defined as an inability to place an endotracheal tube.

For specific Utstein clinical variables, predicted airway difficulty, and aggravating factors, the PRFs were assessed and interpreted by one of the investigators with clinical experience in anaesthesia and/or prehospital care. If there was a case in which there was uncertainty or dispute, the investigators discussed that case in order to make a joint decision on the variable in question in order to resolve the uncertainty, by consensus.

Lastly, a $10 \%$ sample was drawn for manual verification of accuracy of the data capture. Further manual verification of all discrepant and missing data was undertaken. Where necessary, disputes were resolved by a third investigator.

\section{Data Analysis}

Regardless of the data source, data were extracted onto a Microsoft Excel (Microsoft Corporation, Redmond, Washington, United States) spreadsheet. All analyses were conducted using Stata 17.0 (StataCorp, Texas, United States). Continuous variables were summarised as mean and standard deviation; while nominal and ordinal variables were summarised as counts and percentages.

Logistic regression was performed to evaluate the effect of age, sex, reason for emergency treatment, indication for intubation, approach, risk factors, aggravating conditions and scene time on the likelihood of three outcomes: 1) First Pass Success; 2) Overall Success; and 3) Failed Intubation. The outcome was predicted perfectly for two reason variables (infection (including sepsis) and psychiatry (e.g. agitation/psychosis)) and two indication variables (humanitarian and failure of airway device). These variables were thus omitted in the models. This resulted in nine cases being excluded from the FPS model, 83 cases excluded from the overall success model and 220 cases excluded from the failed intubation.

Model fit was assessed based on the Hosmer-Lemeshow ( $\mathrm{HL}$ ) goodness of fit test and inspection of plots for influential observations. Results from the HL tests indicated reasonable fit for all models. Multicollinearity was assessed using the variance inflation factor (VIF). Cardiac arrest and CPR as indications for intubation both had VIF values greater than 10. Cardiac arrest as an indication was excluded and CPR kept for subsequent models. The indicators for "whether or not aggravating conditions were assessed" and "no aggravating conditions indicated", also had VIF values larger than 10. Both 
indicators were kept in the models since it is likely that the distinction between "not assessed" and "no aggravating conditions" cannot be clearly delineated retrospectively.

Cases that were outlying from the other observations in terms of standardised Pearson residuals, leverage values and difference of Chi-square values were excluded from follow-up runs of the models, to evaluate estimates without these observations. Standard errors on the coefficients for the Failed Intubation model improved markedly with the exclusion of one particular case.

\section{Results}

A total of 1339 patients received non-physician performed ETI during the study period. The number of intubation attempts were not recorded in $413(30.8 \%)$ patients, and these were therefore excluded from the primary analyses. This yielded a final sample size of 926 cases with 793 (85.6\%) cases having complete data and $133(14.4 \%)$ cases with at least one missing data point. These cases were therefore excluded from the regression models.

Table 1 describes the demographics of all available cases. The majority of cases were adults $(n=781$, $84.3 \%)$ and male $(n=553,57.6 \%)$. The most common reasons requiring emergency treatment were head injury, including traumatic brain injury (TBI, $n=328,35.4 \%)$, followed by cardiac arrest $(n=204,22.0 \%)$, and blunt trauma $(n=126,13.6 \%)$. The mean time on scene was 46 minutes $(S D=28.3)$.

In Table 2, we present the reasons for intubation as well as the approach taken for intubation. The most cited indication for intubation was decreased level of consciousness ( $n=515,55.6 \%)$, followed by cardiac arrest $(n=242,26.9 \%)$ and ineffective ventilation $(n=96,10.4 \%)$. RSI $(n=344,37.2 \%)$ was the most common mode of intubation, followed by deep sedation $(n=256,27.7 \%)$ and CPR $(n=236,25.5 \%)$.

Table 3 presents the risk factors for difficult intubation and aggravating conditions for airway management. In the 584 cases where risk factors were assessed, only $68(11.6 \%)$ cases stated that no risk factors were present. Of other cases, $62.2 \%(n=363)$ had reduced neck mobility (including manual inline neck stabilisation), 35.1\% ( $n=205)$ had fluid in the airways, while $12.3 \%(n=72)$ of cases had significant facial or airway trauma reported.

In the 732 cases where aggravating conditions for airway management were assessed, 479 (65.4\%) cases had no aggravating conditions. Darkness $(n=96,13.1 \%)$ and intubation in a stationary ambulance $(n=57,7.79 \%)$ were the most common aggravating conditions. In $6.2 \%(n=45)$ of cases the patient was entrapped during intubation while there were hostile conditions on scene in $5.8 \%(n=42)$ of cases.

First pass success (FPS) was achieved in 697 patients, yielding an FPS rate of $75.3 \%$. Intubation failed in $33(3.6 \%)$ patients, yielding an overall all success rate of $95.7 \%(n=886)$.

\section{First pass success}


In a multiple logistic regression model $\left(R^{2}=0.07 ; \mathrm{HL} p=0.96\right)$, adjusting for all variables in Table $S 1$, an indication of ventilation was inversely associated with first pass success $(\mathrm{OR}=0.42,95 \% \mathrm{Cl}: 0.20-0.88$, $\mathrm{p}=0.02)$; deep sedation ( $\mathrm{OR}=0.56,95 \% \mathrm{Cl}: 0.36-0.88, \mathrm{p}=0.13)$ and no drugs ( $\mathrm{OR}=0.47,95 \% \mathrm{Cl}: 0.25$ $0.90, p=0.02)$ compared to RSI was less likely to result in a first pass success; and increased on scene time $(\mathrm{OR}=0.99,95 \% \mathrm{Cl}: 0.985-0.997, \mathrm{p}<0.01)$ was inversely associated with first pass success.

\section{Overall success}

In a multiple logistic regression model $\left(R^{2}=0.24 ; \mathrm{HL} p=0.46\right)$ adjusting for all variables in Table $\mathrm{S} 1$, deep sedation (OR $=0.17,95 \% \mathrm{Cl}: 0.06-0.52, \mathrm{p}<0.01)$ and no drugs $(\mathrm{OR}=0.24,95 \% \mathrm{Cl}: 0.06-0.97, \mathrm{p}=0.04)$ compared to RSI was less likely to result in overall success.

\section{Failed Intubation}

In a multiple logistic regression model $\left(R^{2}=0.29 ; \mathrm{HL} p=0.76\right)$, adjusting for all variables in Table $\mathrm{S} 1$, deep sedation ( $\mathrm{OR}=8.87,95 \% \mathrm{Cl}: 2.30-34.26, \mathrm{p}<0.01)$ and no drugs $(\mathrm{OR}=9.71,95 \% \mathrm{Cl}: 1.95-48.43, \mathrm{p}<0.01)$ compared to RSI was more likely to result in failed intubation. Increased on scene time was also associated with failed intubation failure $(\mathrm{OR}=1.01,95 \% \mathrm{Cl}: 0.999,1.03, \mathrm{p}=0.079)$. 
Table 1

Patient demographics and ETI success

\begin{tabular}{|c|c|c|c|}
\hline & $\begin{array}{l}\text { FPS } \\
n=697(\%)\end{array}$ & $\begin{array}{l}\text { Overall success } \\
\mathrm{n}=886(\%)\end{array}$ & $\begin{array}{l}\text { TOTAL } \\
n=926(\%)\end{array}$ \\
\hline \multicolumn{4}{|l|}{ Age (yrs), n(SD) } \\
\hline Child & $54(7.75)$ & $77(8.69)$ & $79(8.53)$ \\
\hline Adult & $597(85.65)$ & $743(83.86)$ & $781(84.34)$ \\
\hline Unknown & $46(6.60)$ & $66(7.45)$ & $66(7.13)$ \\
\hline \multicolumn{4}{|l|}{ Sex (practitioner assigned) } \\
\hline Male & $391(56.10)$ & $518(58.57)$ & $533(57.56)$ \\
\hline Female & $288(41.32)$ & $346(39.05)$ & $371(40.06)$ \\
\hline Unknown & $18(2.58)$ & $22(2.48)$ & $22(2.38)$ \\
\hline \multicolumn{4}{|c|}{ Predominant reason for emergency treatment } \\
\hline \multicolumn{4}{|l|}{ Trauma } \\
\hline Head injury, incl. TBI & $243(34.86)$ & $325(36.68)$ & $328(35.42)$ \\
\hline Blunt & $95(13.63)$ & $115(12.98)$ & $126(13.61)$ \\
\hline Penetrating & $24(3.44)$ & $24(2.71)$ & $25(2.70)$ \\
\hline Other & $21(3.01)$ & $23(2.60)$ & $23(2.48)$ \\
\hline \multicolumn{4}{|l|}{ Medical } \\
\hline Cardiac arrest & $153(21.95)$ & $195(22.01)$ & $204(22.03)$ \\
\hline Intoxication & $46(6.60)$ & $56(6.32)$ & $62(6.70)$ \\
\hline Respiratory distress or difficulties & $44(6.31)$ & $55(6.21)$ & $58(6.26)$ \\
\hline Other & $10(1.43)$ & $13(1.47)$ & $13(1.40)$ \\
\hline \multicolumn{4}{|l|}{ Neurology } \\
\hline Stroke & $36(5.16)$ & $49(5.53)$ & $54(5.83)$ \\
\hline Other & $24(3.44)$ & 30 (3.39) & $30(3.24)$ \\
\hline
\end{tabular}


Table 2

Indications for and approach to ETI and ETI success

\begin{tabular}{|llll|}
\hline & FPS & Overall success & TOTAL \\
& $\mathbf{n = 6 9 7 ( \% )}$ & $\mathbf{n = 8 8 6 ( \% )}$ & $\mathbf{n = 9 2 6 ( \% )}$ \\
\hline Indication for ETI (multiple/patient) & & \\
\hline Decreased LOC & $382(54.81)$ & $497(56.09)$ & $515(55.62)$ \\
\hline Cardiac Arrest & $192(27.55)$ & $240(27.09)$ & $249(26.89)$ \\
\hline Ineffective ventilation & $62(8.90)$ & $85(9.59)$ & $96(10.37)$ \\
\hline Existing airway obstruction & $33(4.73)$ & $42(4.74)$ & $49(5.29)$ \\
\hline Combative or uncooperative & $42(6.03)$ & $47(5.3)$ & $48(5.18)$ \\
\hline Impending airway obstruction & $39(5.60)$ & $41(4.63)$ & $45(4.86)$ \\
\hline Hypoxemia & $7(1.00)$ & $10(1.13)$ & $11(1.19)$ \\
\hline Humanitarian (e.g. pain relief) & $7(1.00)$ & $7(0.79)$ & $7(0.76)$ \\
\hline Failure of A/W device & $1(0.14)$ & $1(0.11)$ & $1(0.11)$ \\
\hline Approach & & & \\
\hline RSI & $271(38.88)$ & $337(38.04)$ & $344(37.15)$ \\
\hline Deep Sedation & $179(25.68)$ & $238(26.86)$ & $256(27.65)$ \\
\hline Cardiac Arrest & $181(25.97)$ & $226(25.51)$ & $236(25.49)$ \\
\hline No Medication & $65(9.33)$ & $84(9.48)$ & $89(9.61)$ \\
\hline
\end{tabular}


Table 3

Risk factors and aggravating conditions and ETI success

\begin{tabular}{|c|c|c|c|}
\hline & $\begin{array}{l}\text { FPS } \\
n=697(\%)\end{array}$ & $\begin{array}{l}\text { Overall success } \\
\mathrm{n}=886(\%)\end{array}$ & $\begin{array}{l}\text { TOTAL } \\
\mathrm{n}=926(\%)\end{array}$ \\
\hline \multicolumn{4}{|c|}{ Patient risk factors for difficult intubation ${ }^{1}$} \\
\hline Reduced neck mobility (incl. MILNS) & $266(38.16)$ & $355(40.07)$ & $363(39.20)$ \\
\hline Risk factors not assessed & $269(38.59)$ & $324(36.57)$ & $342(36.93)$ \\
\hline Fluid in airways & $145(20.80)$ & $200(22.57)$ & $205(22.14)$ \\
\hline Significant facial or airway trauma & $56(8.03)$ & $70(7.90)$ & $72(7.78)$ \\
\hline No risk factors for difficult intubation & $55(7.89)$ & $63(7.11)$ & $68(7.34)$ \\
\hline Severe obesity or thick/short neck & $11(1.58)$ & $18(2.03)$ & $20(2.16)$ \\
\hline Other & $11(1.58)$ & $15(1.69)$ & $16(1.73)$ \\
\hline Limited mouth opening & $5(0.72)$ & $11(1.24)$ & $12(1.30)$ \\
\hline Pre-existing airway device ineffective & $6(0.86)$ & $7(0.79)$ & $9(0.97)$ \\
\hline Prior difficult intubation & $5(0.72)$ & $7(0.79)$ & $8(0.86)$ \\
\hline Short TMD & $2(0.29)$ & $3(0.34)$ & $3(0.32)$ \\
\hline \multicolumn{4}{|c|}{ Aggravating conditions for airway management ${ }^{2}$} \\
\hline Not assessed & $144(20.66)$ & $174(19.64)$ & $194(20.95)$ \\
\hline Darkness & $68(9.76)$ & $95(10.72)$ & $96(10.37)$ \\
\hline In stationary ambulance & $42(6.03)$ & $50(5.64)$ & $57(6.16)$ \\
\hline Patient entrapped & $35(5.02)$ & $43(4.85)$ & $45(4.86)$ \\
\hline Hostile environment & $35(5.02)$ & $40(4.51)$ & $42(4.54)$ \\
\hline In moving ambulance & $23(3.30)$ & $28(3.16)$ & $29(3.13)$ \\
\hline Not 360-degree access & $12(1.72)$ & $13(1.47)$ & $15(1.62)$ \\
\hline Bright light/sunlight & $9(1.29)$ & $12(1.35)$ & $12(1.30)$ \\
\hline Suboptimal provider positioning & $4(0.57)$ & $5(0.56)$ & $6(0.65)$ \\
\hline
\end{tabular}

\section{Discussion}


This study aimed to describe ETI in South Africa in terms of patient demographics, indications for intubation, means of intubation and success rates. To our knowledge, this is the largest study of paramedic-performed ETI from the African continent and other low-resource settings. We found that most patients who underwent ETI during this period were adults, males, trauma victims, or had a decreased level of consciousness following trauma. Non-physician ETI appeared to have high overall success rates, despite the presence of risk factors for difficult intubation. The most common approach to ETI was RSI.

South Africa, like many other LMICs, has a tremendously high trauma burden. ${ }^{20,21}$ It is therefore not surprising that the predominant reason for emergency care was following injury. Injury, and particularly $\mathrm{TBI}$, is one of the most important contributors to morbidity and mortality in LMICs, especially in the younger, economically active younger population. ${ }^{22}$ Out-of-hospital cardiac arrest was also a common presentation and this is likely reflective of an increasing burden of cardiovascular disease in Sub-Saharan Africa, including South Africa. ${ }^{23} \mathrm{ETI}$ in the setting of cardiac arrest is only recommended under optimal conditions and in settings with demonstrable high success rates, but has further been de-emphasised with chest compressions as the priority. ${ }^{24}$ The utility of ETI in the South African context, where out-ofhospital cardiac arrest survival rates are very low, 25,26 is yet to be determined.

Across the world, non-physician ETI FPS rates range from 47-98\%. ${ }^{27-29}$ Further, a recent systematic review that was limited to ETI with an RSI approach only, found non-physician FPS of $78 \%(95 \% \mathrm{CI}$ [65\%-89\%]). ${ }^{2}$ The FPS rates reported in this study (75\%) compares favourably to that reported in the international literature, despite comprising ETI approaches other than RSI. The use of neuromuscular blocking agents have been found to decrease the risk of difficult intubation, ${ }^{30}$ and yield a higher FPS rate. ${ }^{31}$ This was also demonstrated in our study where RSI was shown to improve the odds of FPS over other approaches. Consequently, these other approaches could have had a lowering effect on the reported FPS. A third of cases had to be excluded because the number of intubation attempts was not recorded. It is not possible to know whether this was more likely to be noted when one or multiple intubation attempts were made. It is therefore conceivable that this could have influenced the reported FPS rate. Similarly, the overall success rates (95.7\%) in this sample also compared favourably to that reported elsewhere (97\% (95\% Cl [95-99\%]) in RSI only. ${ }^{2}$ When comparing these rates with non-physician ETI using multiple approaches, the overall success rate is slightly higher in our study than reported in a recent meta-analysis $\left(91.7\left(95 \%\right.\right.$ Cl 61.6-100)). ${ }^{3}$

Owing to heterogeneity in prehospital emergency medical services across the world in terms of provider profile and skill level, and resourcing, comparisons of FPS is not always appropriate, and this should be taken into consideration when interpreting the results.

Perhaps then, it might be more appropriate to compare our FPS rates in this study with other studies originating from South Africa. A recent retrospective descriptive analysis of ETIs in Helicopter Emergency Medical Services (HEMS) reported a FPS rate of 79\%, and an overall success rate of $98 \%$. ${ }^{14}$ This study included all approaches to ETI, and again compares favourably to the success rates reported herein for 
ground-based EMS. In another study, prehospital emergency care students achieved FPS and overall success rates of $85.2 \%$ and $92.4 \%$ when using an RSI approach only. ${ }^{13}$ This is a higher FPS rate than reported in our study, but this could again be explained by the utility of neuromuscular blocking agents. Lastly, when comparing prehospital with emergency department success rates in South Africa, a recent study reported an FPS of $81.8 \%$, which is considerably higher than reported herein. However, a subanalysis of this sample reveals an FPS rate of $73.3 \%$ in cases where direct laryngoscopy was attempted, versus video laryngoscopy. ${ }^{32}$ Video laryngoscopy was not available in the ground-based EMS involved in this study and thus, the latter FPS is a more appropriate comparison. Another consideration when comparing the FPS rates of this study with our results is the low proportion of trauma patients $(20.9 \%)$. Manual in-line neck stabilisation, common practice during ETI in trauma victims, has been shown to significantly increase difficulty and failure of ETI. ${ }^{33}$

Following multiple regression analysis, three factors remained associated with FPS: RSI approach, ventilation as an indication for intubation, and on scene time. RSI was associated with overall success, and inversely related to failed intubation. The impact of an RSI approach on intubation difficulty and success rates has already been discussed.

On scene time was inversely associated with FPS, while increasing on scene time was associated with overall failure. It is a logical conclusion that the requirement for multiple intubation attempts may prolong scene time, while successfully securing the airway on first attempt will limit the time spent on scene for stabilisation. This was demonstrated in a South African HEMS-based study where the number of clinical interventions were correlated with scene, and every 1 additional intervention increased scene time by approximately 4 minutes. ${ }^{1}$ Importantly though, interventions (with ETI being one of the most prevalent) did not result in a significantly more stable patient. The effect of prolonged scene time on mortality is yet to be determined in the South African context, especially with such a high burden of injury.

Ineffective ventilation as indication for ETI was inversely associated with FPS. This might be explained by the predictable instability associated with acidosis and hypoxaemia that accompany hypoventilation. 34 This may preclude prolonged attempts at securing the airway and result in earlier termination of an intubation attempt to avoid adverse events.

While success rates are a useful measure of airway management, they can be misleading as surrogates for safe ETI. Instead, there is a drive towards reporting of peri-intubation adverse events, rather than simply relying on success rates. In this retrospective study, it was difficult to validly extract AEs from the PRFs as the exact time of intubation was not recorded in most instances. Poor reporting was also the reason why a third of eligible cases where the number of intubation attempts were not recorded, had to be excluded. We therefore suggest that PRFs and/or reporting documents for all PHAAM instances be adjusted to allow for meaningful analysis as part of quality improvement and research practices. Using standardised airway forms has been found to reduce the rate of missing information and significantly increase the quality of data reported during PHAAM. ${ }^{35}$ Calls for standardisation and robust clinical 
governance for PHAAM in South Africa, have been made previously ${ }^{12}$ but there seem to be barriers to their implementation. ${ }^{36}$

During the data collection period of this study, all advanced life support prehospital providers were licensed to intubate patients. In 2020, the Health Professions Council of South Africa (HPCSA) made the decision to remove ETI from the scope of practice of all prehospital providers and subsequently prehospital intubation can only be performed by degreed providers using the RSI approach. Currently, there are only 900 degreed providers registered with the HPCSA, ${ }^{37}$ yet it is unclear how many are actually still in full-time clinical practice in South Africa - a major concern as South Africa has had some considerable challenges in retention of prehospital providers. ${ }^{38,39}$

Emergency intubation in the prehospital environment is a complex intervention with severe complications if it is poorly planned or performed, so optimising all factors involved prior to intubation makes sense. This would include allowing only well-trained, competent individuals with adequate skills and experience to undertake PHAAM. ${ }^{40,41}$ While it can be seen as a commendable decision to reserve intubation for the highest qualified prehospital providers, this might translate into lack of access to a potentially life-saving intervention early in the course of emergency care. This may be undesirable, especially in TBI where early control of oxygenation and ventilation may prevent secondary brain injury 42 - TBI comprised over twothirds of the patients in this study. The potential impact and unintended consequences of removing access to ETI in these patients warrants urgent examination. Some solutions to this may be to develop retention strategies for degreed paramedics and incentivise them to remain in practice, especially in rural or underserved communities. Another option may be regionalised scopes of practice for all ALS that are tailored to anticipated prehospital times and local injury and illness epidemiology.

It is essential to acknowledge the paucity of robust data on the effect of prehospital ETI on morbidity and mortality, ${ }^{43}$ especially in trauma. $6,41,44$ Where data exists, it is mostly from high income settings, or cannot allow for meaningful comparison or meta-analysis owing to health system variation, selective reporting, or risk of bias. There is an urgent need to performance additional research that evaluates the peri-intubation safety and outcome following PHAAM. In our view, the only way that this could happen robustly is through the implementation of mandatory standard reporting databases.

\section{Limitations}

This retrospective study is not without limitations. Data were extracted from self-reported clinical notes that are not intended for research and therefore had to be extracted based on the clinical impression of the extractors. Certain data such as airway difficulty and aggravating factors relating to airway assessment are based on the subjective judgement of the practitioner performing the assessment and can therefore only be considered as estimates of potential airway difficulty. External validity is certainly affected by the inclusion of private services and only one, provincial public emergency medical service. 


\section{Conclusion}

In this sample of ground-based EMS non-physician ETI, we found success rates similar to that reported in international, non-physician literature. Success rates also compared favourably to South African facilitybased rates, when intubation is performed by physicians. RSI, on scene time and ineffective ventilation as an indication for intubation were the most important variables associated with FPS. More research is needed to determine AE rates and the impact of PHAAM on patient outcome. There is an urgent need to standardise PHAAM reporting in South Africa.

\section{Declarations}

\section{Ethical Approval and consent to participate}

Ethical approval was obtained from the Human Research Ethics Committee of the University of Cape Town (HREC ref: 698/2018 and 706/2018), with waiver of informed consent as study was retrospective.

\section{Consent for Publication}

No consent for publication was gained as the study does not any individual person's data.

\section{Availability of data and materials}

The datasets used and analysed during the current study are available form the corresponding author on reasonable request.

\section{Competing interests}

The authors declare that they have no competing interests.

\section{Funding}

This study was self-funded by the authors.

\section{Authors' contribution}

CW conceptualised and designed the study, analysed and interpreted data, and drafted and approved the final manuscript. FA, JB conceptualised and designed the study, collected and analysed data, and approved the final manuscript. IJ contributed to study design and data interpretation, and approved the final manuscript. AH analysed and interpreted data, and approved the final manuscript. WS 
conceptualised and designed the study, analysed and interpreted data, and drafted and approved the final manuscript.

\section{Acknowledgements}

No further acknowledgement

\section{References}

1. van Niekerk G, Welzel T, Stassen W. Clinical Interventions Account for Scene Time in a Helicopter Emergency Medical Service in South Africa. Air Med J [Internet]. Elsevier Inc.; 2018;000:1-5. Available from: https://doi.org/10.1016/j.amj.2018.07.027

2. Fouche PF, Stein C, Simpson P, Carlson JN, Doi SA. Nonphysician Out-of-Hospital Rapid Sequence Intubation Success and Adverse Events: A Systematic Review and Meta-Analysis. Ann Emerg Med [Internet]. 2017 Oct;70(4):449-459.e20. Available from:

https://linkinghub.elsevier.com/retrieve/pii/S0196064417303220

3. Crewdson K, Lockey DJ, Røislien J, Lossius HM, Rehn M. The success of pre-hospital tracheal intubation by different pre-hospital providers: A systematic literature review and meta-analysis. Crit Care. BioMed Central Ltd.; 2017 Feb;21(1).

4. Lossius H, Røislien J, Lockey DJ. Patient safety in pre-hospital emergency tracheal intubation: a comprehensive meta-analysis of the intubation success rates of EMS providers. Crit Care [Internet]. 2012;16(1):R24. Available from: http://ccforum.biomedcentral.com/articles/10.1186/cc11189

5. Davis DP, Dunford J V, Poste JC, Ochs M, Holbrook T, Fortlage D, et al. The impact of hypoxia and hyperventilation on outcome after paramedic rapid sequence intubation of severely head-injured patients. J Trauma [Internet]. 2004 Jul;57(1):1-8; discussion 8-10. Available from:

http://www.ncbi.nlm.nih.gov/pubmed/15284540

6. Sobuwa S, Hartzenberg HB, Geduld H, Uys C. Outcomes following prehospital airway management in severe traumatic brain injury. South African Med J. 2013;103(9):644-6.

7. Mould-Millman N-K, Dixon JM, Sefa N, Yancey A, Hollong BG, Hagahmed M, et al. The State of Emergency Medical Services (EMS) Systems in Africa. Prehosp Disaster Med [Internet]. 2017 Jun [cited 2018 Apr 19];32(03):273-83. Available from: https://www.cambridge.org/core/product/identifier/S1049023X17000061/type/journal_article

8. Eyal N, Cancedda C, Kyamanywa P, Hurst SA. Non-physician Clinicians in Sub-Saharan Africa and the Evolving Role of Physicians. Int J Heal policy Manag [Internet]. 2015 Dec 30;5(3):149-53. Available from: http://www.ncbi.nlm.nih.gov/pubmed/26927585

9. Meara JG, Leather AJM, Hagander L, Alkire BC, Alonso N, Ameh EA, et al. Global Surgery 2030: evidence and solutions for achieving health, welfare, and economic development. Lancet [Internet]. 
2015 Aug;386(9993):569-624. Available from:

https://linkinghub.elsevier.com/retrieve/pii/S014067361560160X

10. Kironji AG, Hodkinson P, de Ramirez SS, Anest T, Wallis L, Razzak J, et al. Identifying barriers for out of hospital emergency care in low and low-middle income countries: a systematic review. BMC Health Serv Res [Internet]. 2018 Dec 19;18(1):291. Available from:

https://bmchealthservres.biomedcentral.com/articles/10.1186/s12913-018-3091-0

11. Gunning M, Perkins Z, Crilly J, von Rahden R. Paramedic Rapid Sequence Intubation (RSI) in a South African Emergency Medical Service (EMS) is effective, but is it safe? Scand J Trauma Resusc Emerg Med. BioMed Central Ltd; 2013;21(S1):S29.

12. Stein C, Botha M, Kramer E, Nevin D, Dickerson R, Goldstein L, et al. Position statement. Pre-hospital rapid sequence intubation. S Afr Med J. 2011;101(3):163.

13. Stein C. Student paramedic rapid sequence intubation in Johannesburg, South Africa: A case series. African J Emerg Med [Internet]. 2017 Jun;7(2):56-62. Available from: https://linkinghub.elsevier.com/retrieve/pii/S2211419X16300805

14. Stassen W, Lithgow A, Wylie C, Stein C. A descriptive analysis of endotracheal intubation in a South African Helicopter Emergency Medical Service. African J Emerg Med Rev africaine la Med d'urgence [Internet]. 2018 Dec;8(4):140-4. Available from: http://www.ncbi.nlm.nih.gov/pubmed/30534517

15. Benchimol El, Smeeth L, Guttmann A, Harron K, Moher D, Petersen I, et al. The REporting of studies Conducted using Observational Routinely-collected health Data (RECORD) Statement. PLOS Med [Internet]. 2015 Oct 6;12(10):e1001885. Available from: https://dx.plos.org/10.1371/journal.pmed.1001885

16. Statistics SA. General Household Survey [Internet]. Statistical Release P0318. Pretoria; 2016. Available from: https://www.statssa.gov.za/publications/P0318/P03182016.pdf

17. Health Professions Council of South Africa. Clinical Practice Guidelines for Emergency Care Providers [Internet]. 2018. Available from: https://www.hpcsa.co.za/Uploads/EMB/CLINICAL PRACTICE GUIDELINES - PROTOCOLS- JULY 2018.pdf

18. HPCSA. Health Professions Council of South Africa Professional Board for Emergency Care Capabilities of Emergency Care Providers [Internet]. 2011 [cited 2018 Feb 12]. p. 2-4. Available from: http://www.hpcsa.co.za/downloads/emergency_care/capabilites_june_2011.pdf

19. Sunde GA, Kottmann A, Heltne JK, Sandberg M, Gellerfors M, Krüger A, et al. Standardised data reporting from pre-hospital advanced airway management - a nominal group technique update of the Utstein-style airway template. Scand J Trauma Resusc Emerg Med [Internet]. 2018 Jun 4;26(1):46. Available from: http://www.ncbi.nlm.nih.gov/pubmed/29866144

20. Naghavi M, Wang H, Lozano R, Davis A, Liang X, Zhou M, et al. Global, regional, and national age-sex specific all-cause and cause-specific mortality for 240 causes of death, 1990-2013: A systematic analysis for the Global Burden of Disease Study 2013. Lancet. 2015;385(9963):117-71.

21. Norman R, Matzopoulos R, Groenewald P, Bradshaw D. The high burden of injuries in South Africa. Bull World Health Organ [Internet]. 2007 Sep [cited 2019 Apr 17];85(9):695-702. Available from: 
http://www.ncbi.nlm.nih.gov/pubmed/18026626

22. Adegboyega G, Zolo Y, Sebopelo LA, Dalle DU, Dada OE, Mbangtang CB, et al. The Burden of Traumatic Brain Injury in Sub-Saharan Africa: A Scoping Review. World Neurosurg. United States; 2021 Sep;

23. Onen CL. Epidemiology of ischaemic heart disease in sub-Saharan Africa: review article. Cardiovasc J Afr [Internet]. 2013 Mar 28;24(2):34-42. Available from:

http://www.cvja.co.za/onlinejournal/vol24/vol24_issue2/\#/36/zoomed

24. Panchal AR, Bartos JA, Cabañas JG, Donnino MW, Drennan IR, Hirsch KG, et al. Part 3: Adult Basic and Advanced Life Support: 2020 American Heart Association Guidelines for Cardiopulmonary Resuscitation and Emergency Cardiovascular Care. Circulation. 2020 Oct 20;142(16_suppl_2):S366468.

25. Stassen W, Wylie C, Djärv T, Wallis L. Out-of-hospital cardiac arrests in the city of Cape Town, South Africa: A retrospective, descriptive analysis of prehospital patient records. BMJ Open. 2021;11(e049141).

26. Stein C. Out-of-hospital cardiac arrest cases in Johannesburg, South Africa: a first glimpse of shortterm outcomes from a paramedic clinical learning database. Emerg Med J [Internet]. British Association for Accident and Emergency Medicine; 2009 Sep 1 [cited 2018 Oct 30];26(9):670-4. Available from: http://www.ncbi.nlm.nih.gov/pubmed/19700590

27. Delorenzo A, St Clair T, Andrew E, Bernard S, Smith K. Prehospital Rapid Sequence Intubation by Intensive Care Flight Paramedics. Prehospital Emerg Care. Taylor \& Francis; 2018;22(5):595-601.

28. Peters J, Wageningen B, Hendriks I, Eijk R, Edwards M, Hoogerwerf N, et al. First-pass intubation success rate during rapid sequence induction of prehospital anaesthesia by physicians versus paramedics. Eur J Emerg Med. 2014 May;Publish Ah.

29. Phelps S, Peters J, Van Wageningen B, Hendriks I, Eijk R, Edwards M, et al. Intubation success rates of prehospital rapid sequence induction of anaesthesia by physicians versus paramedics. Eur $\mathrm{J}$ Emerg Med. 2017;24(1):76-7.

30. Lundstrøm LH, Duez CHV, Nørskov AK, Rosenstock CV, Thomsen JL, Møller AM, et al. Effects of avoidance or use of neuromuscular blocking agents on outcomes in tracheal intubation: a Cochrane systematic review. Br J Anaesth [Internet]. 2018 Jun;120(6):1381-93. Available from: https://linkinghub.elsevier.com/retrieve/pii/S0007091217542130

31. Okubo M, Gibo K, Hagiwara Y, Nakayama Y, Hasegawa K, Japanese Emergency Medicine Network Investigators. The effectiveness of rapid sequence intubation (RSI) versus non-RSI in emergency department: an analysis of multicenter prospective observational study. Int J Emerg Med [Internet]. 2017 Dec;10(1):1. Available from: http://www.ncbi.nlm.nih.gov/pubmed/28124199

32. Hart JC, Goldstein LN. Analysis of the airway registry from an academic emergency department in South Africa. S Afr Med J [Internet]. 2020 May 29;110(6):484-90. Available from: http://www.ncbi.nlm.nih.gov/pubmed/32880559 
33. Thiboutot F, Nicole PC, Trépanier CA, Turgeon AF, Lessard MR. Effect of manual in-line stabilization of the cervical spine in adults on the rate of difficult orotracheal intubation by direct laryngoscopy: a randomized controlled trial. Can J Anesth Can d'anesthésie [Internet]. 2009 Jun 24;56(6):412-8. Available from: http://link.springer.com/10.1007/s12630-009-9089-7

34. Mosier JM, Joshi R, Hypes C, Pacheco G, Valenzuela T, Sakles JC. The Physiologically Difficult Airway. West J Emerg Med [Internet]. 2015 Dec;16(7):1109-17. Available from: http://www.ncbi.nlm.nih.gov/pubmed/26759664

35. Bloomer R, Burns BJ, Ware S. Improving documentation in prehospital rapid sequence intubation: Investigating the use of a dedicated airway registry form. Emerg Med J. 2013;30(4):324-6.

36. Botha JC, Lourens A, Stassen W. Rapid sequence intubation: a survey of current practice in the South African pre-hospital setting. Int J Emerg Med [Internet]. 2021 Dec 17;14(1):45. Available from: https://intjem.biomedcentral.com/articles/10.1186/s12245-021-00368-3

37. Health Professions Council of South Africa. Registration Statistics [Internet]. 2021 [cited 2021 Nov 14]. Available from: https://www.hpcsa.co.za/?contentld=412\&actionName=Publications

38. Hackland S, Stein C. Factors influencing the departure of South African advanced life support paramedics from pre-hospital operational practice q. African J Emerg Med [Internet]. 2011 [cited 2018 Aug 19];1:62-8. Available from: www.sciencedirect.com

39. Govender K, Grainger L, Naidoo R, MacDonald R. The pending loss of advanced life support paramedics in South Africa. African J Emerg Med [Internet]. African Federation for Emergency Medicine; 2012;2(2):59-66. Available from: http://dx.doi.org/10.1016/j.afjem.2011.11.001

40. Lockey DJ, Healey B, Crewdson K, Chalk G, Weaver AE, Davies GE. Advanced airway management is necessary in prehospital trauma patients. $\mathrm{Br} J$ Anaesth [Internet]. 2015 Apr;114(4):657-62. Available from: https://linkinghub.elsevier.com/retrieve/pii/S0007091217316793

41. Bossers SM, Schwarte LA, Loer SA, Twisk JWR, Boer C, Schober P. Experience in Prehospital Endotracheal Intubation Significantly Influences Mortality of Patients with Severe Traumatic Brain Injury: A Systematic Review and Meta-Analysis. PLoS One [Internet]. 2015;10(10):e0141034. Available from: http://www.ncbi.nlm.nih.gov/pubmed/26496440

42. Spaite DW, Hu C, Bobrow BJ, Chikani V, Barnhart B, Gaither JB, et al. The Impact of Combined Prehospital Hypotension and Hpoxia on Mortality in Major Traumatic Brain Injury. Ann Emerg Med. 2017;69(1):62-72.

43. Wang C-H, Lee A-F, Chang W-T, Huang C-H, Tsai M-S, Chou E, et al. Comparing Effectiveness of Initial Airway Interventions for Out-of-Hospital Cardiac Arrest: A Systematic Review and Network Metaanalysis of Clinical Controlled Trials. Ann Emerg Med [Internet]. 2020;75(5):627-36. Available from: http://www.ncbi.nlm.nih.gov/pubmed/31983493

44. Fevang E, Perkins Z, Lockey D, Jeppesen E, Lossius HM. A systematic review and meta-analysis comparing mortality in pre-hospital tracheal intubation to emergency department intubation in trauma patients. Crit Care. Critical Care; 2017;21(1). 


\section{Supplementary Files}

This is a list of supplementary files associated with this preprint. Click to download.

- PHETISouthAfricaRECORD.docx

- Tables1.docx 